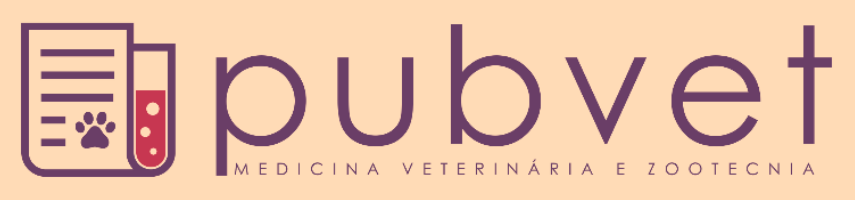

https://doi.org/10.31533/pubvet.v13n01a242.1-5

\title{
Retalho cutâneo da artéria epigástrica superficial caudal no reparo de avulsão de pele em gato
}

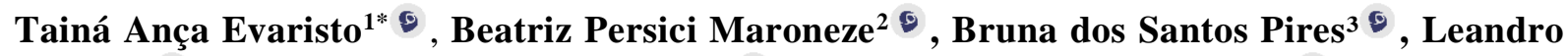 \\ Gaiga $^{4 * \odot \text {, Mariana Cardoso Sanches }{ }^{5 *} \odot \text {, Carla Lempk Constantin }}{ }^{6^{*}} \odot$, Alexsander

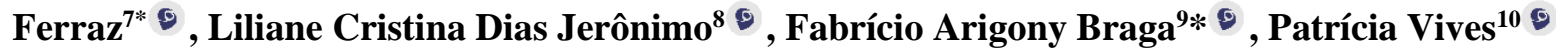 \\ ${ }^{1}$ Graduanda em Medicina Veterinária - Universidade Federal de Pelotas (UFPel); Pelotas-RS; Brasil. \\ ${ }^{2}$ Médica Veterinária. Especialista em Clínica Médica Cirúrgica de Animais de Companhia - UFPel, Pelotas-RS; Brasil \\ ${ }^{3}$ Médica Veterinária; Pós-graduanda em Clínica Médica Cirúrgica de Animais de Companhia, UFPel, Pelotas-RS, Brasil \\ ${ }^{4}$ Médico Veterinário; MsC. Especialista em Ortopedia. Porto Alegre-RS, Brasil. \\ ${ }^{5}$ Médica Veterinária; Especialista em Anestesiologia de Animais de Companhia, Pelotas-RS \\ ${ }^{6}$ Médica Veterinária. Porto Alegre-RS, Brasil. \\ ${ }^{7} \mathrm{MsC}$ em Fisiologia Animal; Especialista em Zoonoses Parasitárias; Doutorando em Clínica de Pequenos Animais - UFPel, Pelotas-RS; Brasil \\ ${ }^{8}$ Médica Veterinária; Pelotas-RS; Brasil. \\ ${ }^{9}$ Dr. em Clínica Cirúrgica de Animais de Companhia; Docente, UFPel, Pelotas-RS \\ ${ }^{10}$ Dra. em Cirurgia e Clínica de Pequenos Animais; Médica Veterinária Técnica em Educação-UFPel \\ *Autor para correspondência, E-mail: evaristo.medvet@gmail.com
}

\begin{abstract}
RESUMO. Os flapes ou retalhos podem ser empregados em diversas ocasiões e de diferentes formas, um deles é o retalho cutâneo pediculado da artéria epigástrica superficial caudal. Esta técnica é indicada para cobrir defeitos cutâneos em abdômen caudal, flanco, prepúcio e períneo. O procedimento pode ser utilizado em fêmeas e machos, em cães e gatos. Objetivou-se relatar a utilização de retalho de padrão axial epigástrico superficial caudal em um felino acometido por avulsão dérmica extensa em membro pélvico direito.
\end{abstract}

Palavras chave: autoenxerto, flape, felino, retalho padrão axial

\section{Cutaneous patch of the caudal superficial epigastric artery in the repair of avulsion of skin on cat}

ABSTRACT. Flaps or patchwork can be used on several occasions and in different ways, one of which is the pedicled skin flap of caudal superficial epigastric artery. This technique is indicated to cover skin defects in caudal abdomen, flank, foreskin and perineum. The procedure can be used in females and males, in dogs and cats. The purpose of this study was to report the use of caudal superficial epigastric axial flap in a feline affected by extensive dermal avulsion in the right pelvic limb.

Keywords: autograft, flap, feline, axial standard flap

\section{Retraso cutáneo de la arteria epigástrica superficial caudal en la reparación de avulsión de piel en gato}

RESUMEN. Los flapes o retazos pueden ser empleados en diversas ocasiones y de diferentes formas, uno de ellos es el colgajo cutáneo pediculado de arteria epigástrica superficial caudal. Esta técnica está indicada para cubrir defectos cutáneos en el abdomen caudal, flanco, prepucio e perineo. El procedimiento puede ser utilizado en hembras y machos, en perros y gatos. Se objetivó relatar la utilización de colgajo de patrón axial epigástrico superficial caudal en un felino acometido por avulsión dérmica extensa en miembro pélvico derecho.

Palabras clave: autoinjerto, flap, felino, colgajo estándar axial 


\section{Introdução}

A pele é o maior órgão dos seres humanos e dos animais, recobrindo toda a superfície corpórea; exerce diferentes funções, entre elas, proteção contra microrganismos, traumatismos, agentes químicos e radiação. Além disso, colabora para a termo regulação, impede a perda de água, servindo como reservatório de eletrólitos, lipídeos, carboidratos, proteínas e excreção de substâncias (Amâncio et al, 2006).

O termo "cirurgia reconstrutiva" faz referência à utilização de técnicas de reconstrução tecidual, bem como flaps, enxertos, retalhos feitos de pele hígida, possibilitando o fechamento de lesões com ampla extensão (Coltro et al, 2011).

Os retalhos pediculados, também chamados de flape de epiderme e derme, são segmentos com inserção vascular, retirados de um local doador e utilizados no reparo de feridas (Slatter 2007; Fossum 2014). Segundo Fossum (2014), a base ou o pedículo deve conter o suprimento sanguíneo essencial para a sobrevivência do retalho. Os flapes podem ser classificados de diversas formas com base na localização, vascularização e formação do tecido e ainda pode ser de padrão axial, quando é irrigado por artéria e veia cutânea direta, ou do plexo subdérmico possuindo somente irrigação local (Slatter 2007).

O sucesso das técnicas de enxertia de flaps depende, principalmente, das estruturas que estão comprometidas, assim como a extensão da lesão, a preservação da microcirculação e dos cuidados de manipulação dos tecidos. Além disso, deve-se realizar um planejamento cirúrgico minucioso, considerando a qualidade do leito da ferida, o aporte sanguíneo e o tecido disponível (Daleck et al, 2016). A viabilidade do flape de padrão axial depende do estabelecimento de veias, artérias e da drenagem adequada nos primeiros dias de pós-operatório e a má aceitação de retalho está relacionada ao excesso de tecido de granulação, contaminação e/ou debris no local receptor (Slatter 2007).

O objetivo do presente trabalho é relatar o caso de um felino acometido por avulsão cutânea extensa em membro pélvico direito submetido ao reparo cirúrgico por meio do recobrimento com auto-enxerto de retalho cutâneo da artéria epigástrica superficial caudal.

\section{Relato de caso}

Foi encaminhado para atendimento um gato, macho, sem raça definida, com aproximadamente dois anos de idade, que havia sido recolhido em via pública, apresentando avulsão cutânea extensa no membro pélvico direito (Figura 1A).

A internação foi preconizada por alguns dias para estabilização, realização de exames complementares (hemograma e bioquímico), desbridamento e descontaminação da lesão, para sequencialmente ser encaminhado ao reparo cirúrgico.

Após preparo pré-cirúrgico de rotina e plano anestésico adequado, o paciente foi posicionado em decúbito dorsal, a largura e o comprimento da lesão foram aferidos e o leito receptor foi preparado removendo-se as bordas (Figura 1B). A técnica preconizou a confecção de um flape de pele a partir das mamas abdominal cranial, abdominal caudal e inguinal, iniciando por uma incisão elíptica ao redor deste segmento da cadeia mamária direita (Figura 1C), e uma incisão linear a partir da primeira incisão desde a região inguinal e estendendo-se distalmente em direção a lesão do membro pélvico direito. Após a demarcação, o retalho foi divulsionado cuidadosamente por meio de dissecação profunda junto à fáscia muscular abdominal incluindo a artéria epigástrica superficial caudal, exceto na extremidade caudal (Figura 1D). Ato contínuo, o flape foi rotacionado em direção ao membro pélvico direito passando através da incisão inicial e posicionando-o sobre o leito receptor. As bordas foram coaptadas e suturadas com pontos isolados simples utilizando-se náilon monofilamentado 3-0 (Figura 1E e 1F) e na sequencia fez-se atadura acolchoada envolvendo o membro direito (Figura 1G).

Foi administrado tramadol (3 mg/kg) via subcutânea a cada 12 horas (BID) por cinco dias, sulfametaxazol e trimetoprim $(22 \mathrm{mg} / \mathrm{kg})$, via oral, BID, por sete dias, meloxicam $(0,1 \mathrm{mg} / \mathrm{kg})$, via oral, uma vez ao dia (SID) por três dias e curativos BID com atadura elástica justaposta por 30 dias. Após este período, o enxerto apresentava-se completamente incorporado, não edemaciado e discretas áreas de tecido de granulação sobre as articulações do joelho, calcâneo e metatarsos (Figura 1H). 

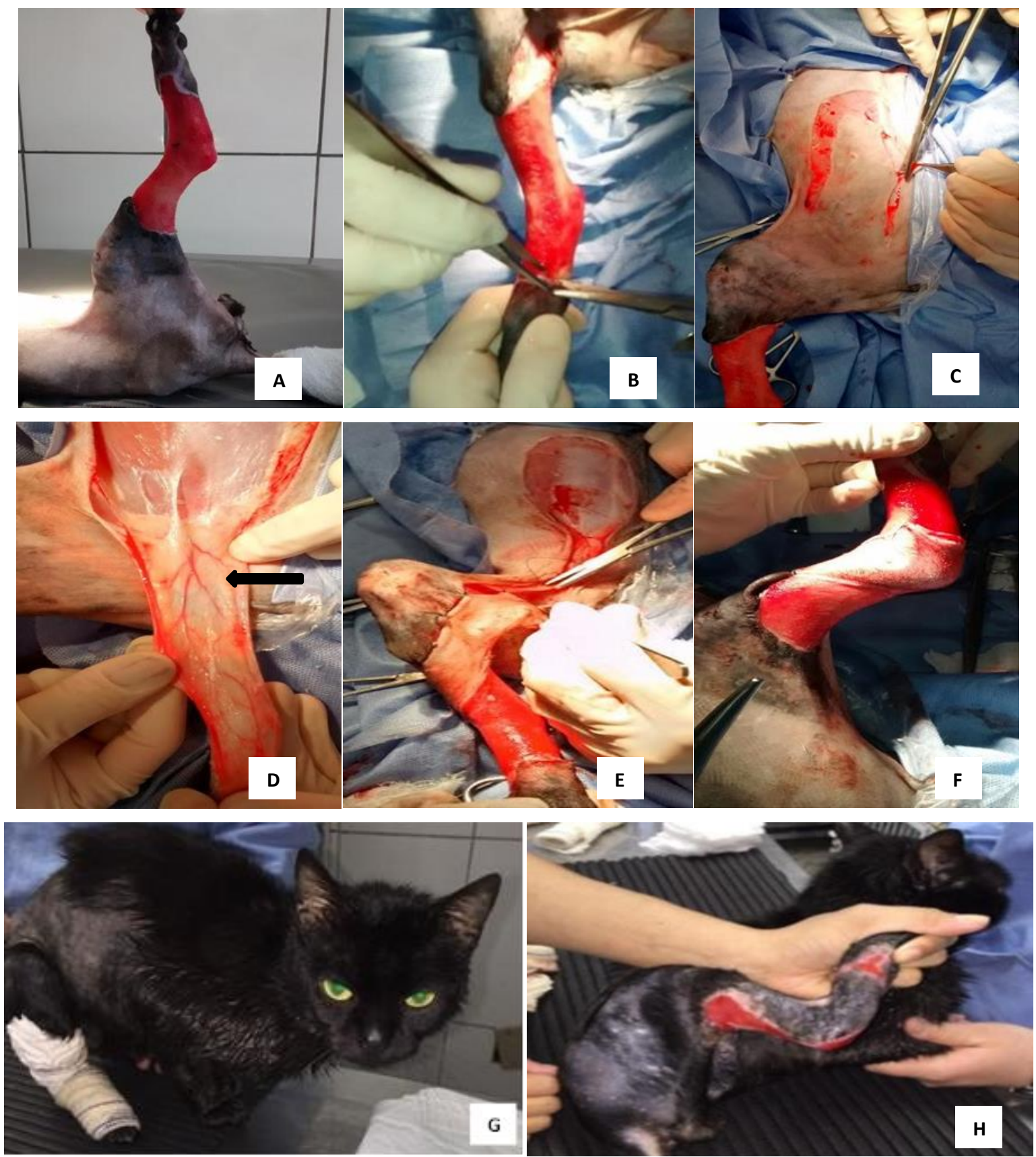

Figura 1: (A) Avulsão cutânea em membro pélvico direito de um felino; (B) Preparo do leito cutâneo receptor removendo-se as bordas de tecido necrosado. (C) Incisão elíptica ao redor do segmento caudal da cadeia mamária direita; (D) Vascularização da epigástrica caudal incluída no flape pediculado (seta); (E e F) Posicionamento do retalho sobre o defeito e sutura das bordas com pontos isolados simples com náilon 3-0; (G) Paciente com curativo acolchoado no pós-operatório; $(\mathrm{H})$ aspecto da lesão cinco semanas após procedimento cirúrgico; Fonte: Arquivo pessoal.

O paciente teve alta clínica 60 dias após, uma vez que houve recobrimento satisfatório da lesão e o retalho assemelhou-se a pele do membro quanto ao crescimento de pêlos, coloração, textura e elasticidade e ao $90^{\circ}$ dia apresentava completa cicatrização e mobilidade satisfatória do membro.

\section{Discussão}

Feridas extensas com perda tecidual importante podem ter reepitelização demorada na forma de segunda intenção, e a cirurgia reconstrutiva por retalhos cutâneos estão indicadas, objetivando reduzir o tempo cicatricial (Slatter 2007), fato evidenciado neste paciente, uma vez que o tempo de cicatrização foi precoce, embora em algumas bordas e sobre o calcâneo tenha sido por segunda intenção. Existem diversas técnicas de reconstrução cutânea, no entanto, a escolha deve considerar a localização da lesão, tamanho, as linhas de tensão, bordas viáveis e disponibilidade de pele 
(Shridharani et al, 2010), e o sucesso na incorporação do enxerto também depende das condições do leito receptor, justificando o tratamento prévio com limpeza e descontaminação da ferida.

A escolha por um retalho de pele em padrão axial está indicada uma vez que a superfície doadora permite mobilizar grande segmento de pele um único procedimento, mantendo boa irrigação e bom arco de rotação (Slatter 2007), conforme no caso descrito, permitindo recobrimento de toda a superfície exposta. Os retalhos de padrão axial possuem em sua base uma artéria e uma veia cutânea de forma pediculada conferindo excelente irrigação e adequada flexibilidade rotacional (Kirpensteijn \& Haar 2013), com elevada indicação para o recobrimento de lesões recentes em membros, visto que esta área receptora possui vascularização reduzida (Fowler 2004; Pavletic 2010). Para evitar ou minimizar complicações, a técnica requer observar os princípios básicos da cirurgia reconstrutiva, que envolvem planejamento cuidadoso, avaliação da ferida e sua localização anatômica, avaliação do grau de elasticidade da pele, empregando-se técnica meticulosa e atraumática (Pazzini \& Moraes 2015; Daleck et al, 2016).

No pós-cirúrgico as complicações podem ser divididas em três grupos: relacionadas à condição geral do paciente, à área receptora e a técnica empregada (Nelson \& Couto 2015). As mais comuns incluem deiscência de pontos, contaminação, formação de seroma e necrose tecidual nas extremidades do retalho (Ehrhart \& Culp 2012). Todavia, no presente relato não houve ocorrência de complicações maiores, exceto a deiscência de poucos pontos e sobre o calcâneo.

A prevenção do seroma se deve a adequada redução do espaço morto, bandagens de compressão suave e compressas mornas (Chung et al, 2009; Withrow et al, 2014). Entretanto, deiscência, infecções e edemas, podem ser evitados pelo emprego de anti-inflamatórios e antibioticoterapia de amplo espectro no pós-operatório (Tobias \& Johnston 2013), conforme conduta preconizada na descrição deste caso. Fossum (2014) recomenda a ovário-histerectomia concomitante nas fêmeas submetidas a esta técnica, pois as glândulas mamárias transpostas no retalho permanecem funcionais. Além disso, os mamilos a podem ser seccionados se a aparência for desagradável aos olhos do tutor, contudo, no presente caso o paciente era macho, não requerendo tais procedimentos associados.

\section{Conclusão}

O retalho cutâneo pediculado de padrão axial da artéria epigástrica superficial caudal foi efetivo na reposição tecidual deste gato, contribuindo para o recobrimento dérmico precoce, reduzindo o tempo de exposição subcutânea e assim promovendo o retorno funcional do membro acometido.

\section{Referências bibliográficas}

Amâncio A.C.G., Barbieri C.H., Mazzer N., Garcia S.B. \& Thomazini J.A. (2006). Estimulação ultrasônica da integração de enxertos de pele total. Estudo experimental em coelhos. Acta Ortopedica Brasileira 14, 276-279.

Chung K.C., Swanson J.A., Schmitz D., Sullivan D. \& Rohrich R.J. (2009). Introducing evidencebased medicine to plastic and reconstructive surgery. Plastic and reconstructive surgery 123, 13851389.

Coltro P.S., Ferreira M.C., Batista B.P.S.N., Nakamoto H.A., MilCheski D.A. \& Tuma Junior P. (2011). Atuação da cirurgia plástica no tratamento de feridas complexas. Revista do Colégio Brasileiro de Veterinária 38, 381-386.

Daleck C.R., Fonseca C.S. \& Canola J.C. (2016). Oncologia em cães e gatos. Roca, Rio de Janeiro.

Ehrhart N. \& Culp W.T.N. (2012). Principles of surgical oncology. In: Veterinary Surgical Oncology, USA: Ed.Wiley-Blackwell, pp.03-15. (eds. by Kudnig ST \& Séguin B), pp. 3-15. Ed.WileyBlackwell, USA.

Fossum T.W. (2014). Cirurgia de pequenos animais. Elsevier Brasil, São Paulo.

Fowler D. (2004). Retalhos de pele. In: Segredos em cirurgia de pequenos animais (ed. by Harara J), pp. 98-101. Artmed, Porto Alegre, Rio Grande do Sul.

Kirpensteijn J. \& Haar G. (2013). Reconstructive surgery and wound management of the dog and cat. Manson Publishing, Ltd., USA. 
Nelson R.W. \& Couto C.G. (2015). Medicina interna de pequenos animais. Elsevier Editora, Amsterdan.

Pavletic M. (2010). Atlas of small animal wound management and reconstructive surgery. Wiley Blackwel, Cambridge, UK.

Pazzini J.M. \& Moraes P.C. (2015). Princípios e técnicas de cirurgias reconstrutivas da pele de cães e gatos: Atlas colorido. Medvep, Curitiba 1, 95-102.

Shridharani S.M., Magarakis M., Manson P.N. \& Rodriguez E.D. (2010). Psychology of plastic and reconstructive surgery: a systematic clinical review. Plastic and reconstructive surgery 126, 22432251.

Slatter D.H. (2007). Manual de cirurgia de pequenos animais. Manole, São Paulo.

Tobias K.M. \& Johnston S.A. (2013). Veterinary Surgery: Small Animal-E-BOOK: 2-Volume Set. Elsevier Health Sciences, St. Louis, USA.

Withrow S.J., Page R. \& Vail D.M. (2014). Small animal clinical oncology. Elsevier Health Sciences, St. Louis.

Recebido: 6 outubro, 2018

Aprovado: 5 novembro, 2018.

Publicado: 31 dezembro, 2018

Licenciamento: Este artigo é publicado na modalidade Acesso Aberto sob a licença Creative Commons Atribuição 4.0 (CC-BY 4.0), a qual permite uso irrestrito, distribuição, reprodução em qualquer meio, desde que o autor e a fonte sejam devidamente creditados. 